\title{
NUCLEAR SCIENCE USER FACILITIES (NSUF) MONTHLY REPORT MARCH 2015
}

\author{
Renae Soelberg
}

March 2015

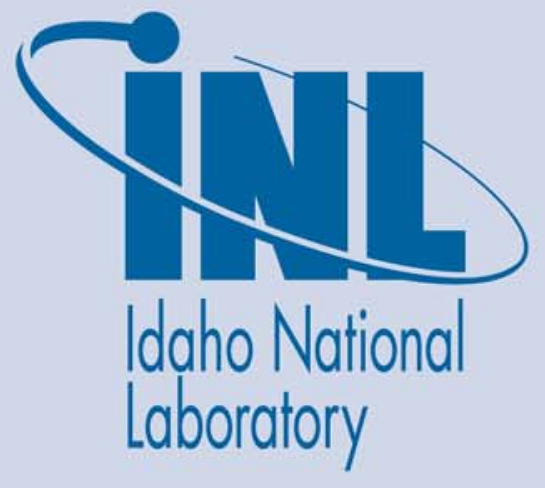

The INL is a U.S. Department of Energy National Laboratory operated by Battelle Energy Alliance 
INL/EXT-15-34739

\title{
NUCLEAR SCIENCE USER FACILITIES (NSUF) MONTHLY REPORT MARCH 2015
}

\author{
Renae Soelberg
}

March 2015

\section{Idaho National Laboratory \\ Idaho Falls, Idaho 83415}

http://www.inl.gov

\author{
Prepared for the \\ U.S. Department of Energy \\ Office of Nuclear Energy \\ Under DOE Idaho Operations Office \\ Contract DE-AC07-05ID14517
}




\section{Nuclear Science User Facilities (NSUF)}

\section{Formerly: Advanced Test Reactor National Scientific User Facility (ATR NSUF) \\ Monthly Report}

March 2015

\section{Highlights}

- Jim Cole and Brenden Heidrich participated in the NE-4 infrastructure review panels.

- Jeff Benson, Donna Guillen Assel Aitkaliyeva, and Sarah Robertson attended The Minerals, Metals and Materials Society (TMS) conference. Donna presented a paper, "Radiation Effects on the Thermophysical Properties of a New Neutron Absorbing Material," (INL-CON-14-32122) with the results of the PIE performed on the Utah State University NSUF experiment. She was also asked to present a second paper to replace a cancellation. The paper is titled "Development of Metal Matrix Composite Material for Nuclear Reactor Applications," (INL-CON-15-34609). She also served as chair of the TMS Energy Committee; representative to the Light Metals Division; organizer for the Energy Technologies and Carbon Dioxide Management symposium; and cochair for the Metal Processing and Molten Salt/Electrochemistry sessions. Assel presented a paper "Fuel-cladding chemical interaction effects in U, Pu-based fuels and cladding" (INL-CON14-32116), with the results of NSUF RTE 14-499.

\section{Milestones}

- Brenden Heidrich completed the level three milestone, "Identify and document NE R\&D capabilities." The Database Review Panel report "Nuclear Energy Infrastructure Database Fitness and Suitability Review" INL/EXT-15-34453 was completed and reviewed. The report is submitted as evidence of the creation and population of the Nuclear Energy Infrastructure Database. The database serves to identify and document major nuclear energy-related RD\&D capabilities.

\section{Major Accomplishments/Activities}

\section{Upcoming Meetings/Events}

- Rory Kennedy, NSUF staff, and DOE HQ staff will be visiting most of the partner facilities in March and April.

\section{Research Project Highlights}

Drexel MAX (09-204) - TEM and XRD analysis of the TiAl and TiSiC specimens for capsules D, E and F has been completed. Specimens from Capsules $\mathrm{H}$ and $\mathrm{J}$ have been shipped from HFEF to EML, potted and cleaned for shipment to CAES. Darin Tallman, Drexel University student PI, will return to CAES in late March, working towards completing his degree. The project will work with Darin to determine what specimens need to be analyzed to complete his studies. 
Utah State University (09-157) - The project has received approval to send nine specimens to IRC to be analyzed using the laser flash, completing work that has been delayed for months due to equipment problems at MFC. Shipment of additional specimens from HFEF (for tensile testing and hardness testing) is expected to take place in late March.

University of Central Florida (UCF) (10-242) - The shipment of TEM and foil specimens from HFEF to EML has been completed. The project is waiting for direction from the INL PI to determine how to proceed with analysis.

University of California-Berkley (UCB) (10-244) - University of California-Berkeley principal investigator Mehdi Balooch visited PNNL to observe measurements and help finalize plans for completing the desired suite of analyses. His visit was coordinated to coincide with the visit of Jim Lane and Doug Copsey who are helping to prepare the annual report.

University of California-Santa Barbara-2 (09-153) - Disassembly of the capsule has been initiated, but could not be completed because the packets could not be separated from the inner tube. Additional tooling, a small portable mill, is being fabricated to assist in disassembly. Slitting the tubing will be difficult given the hardened condition of the cladding. If successful, the packets should be able to be easily slipped out of the tubing and prepared for shipment to ORNL. Isotopic calculations have been provided to ORNL for review and approval. With delays in HFEF, shipment is expected in early May.

EPRI Pilot Program: Irradiation and PIE of X-750 and XM-19 (CRADA 12-CR-06) - Irradiation of the second test train for this project was completed on Feb. 17. The EPRI-1 test train was irradiated to a nominal fluence of $5.0 \times 10^{\wedge} 19 \mathrm{n} / \mathrm{cm}^{\wedge} 2$ in a short, five-day cycle in the ATR Center Flux Trap and utilizing Loop 2A. The irradiation marks the completion of the second of three test train irradiations. The final test train (EPRI-3) will be inserted in a future, full cycle in order to accumulate its target fluence equal to approximately $1.0 \times 10^{\wedge} 21 \mathrm{n} / \mathrm{cm}^{\wedge} 2$. The EPRI-1 capsule will now be placed in the ATR pool; depending on testing results that are currently being obtained, this capsule may be a candidate for further irradiation at a later date. 